Met Office

\title{
Committed Terrestrial Ecosystem changes due to climate change
}

Chris Jones*, Stephen Sitch, Philippe Ciais, Pierre Friedlingstein, Chris Huntingford, Peter Levy, Mark Lomas, Shilong Piao, lan Woodward 


\section{Overview}

\section{Met Office}

- Recap

- Climate change and impacts on ecosystems

- Amazon forest dieback

- Concept of committed changes to ecosystems

- Ecosystems have inertia

- Continue to change post-stabilisation

- Explore multi-model uncertainty

- DGVMs and the IMOGEN framework

- What's robust and where does ecosystem uncertainty lie?

- Importance of local feedbacks and coupled modelling 


\section{Future vegetation changes}

\section{Met Office}

- Early climate-carbon cycle GCM simulation showed significant loss of Amazon forest under climate change.

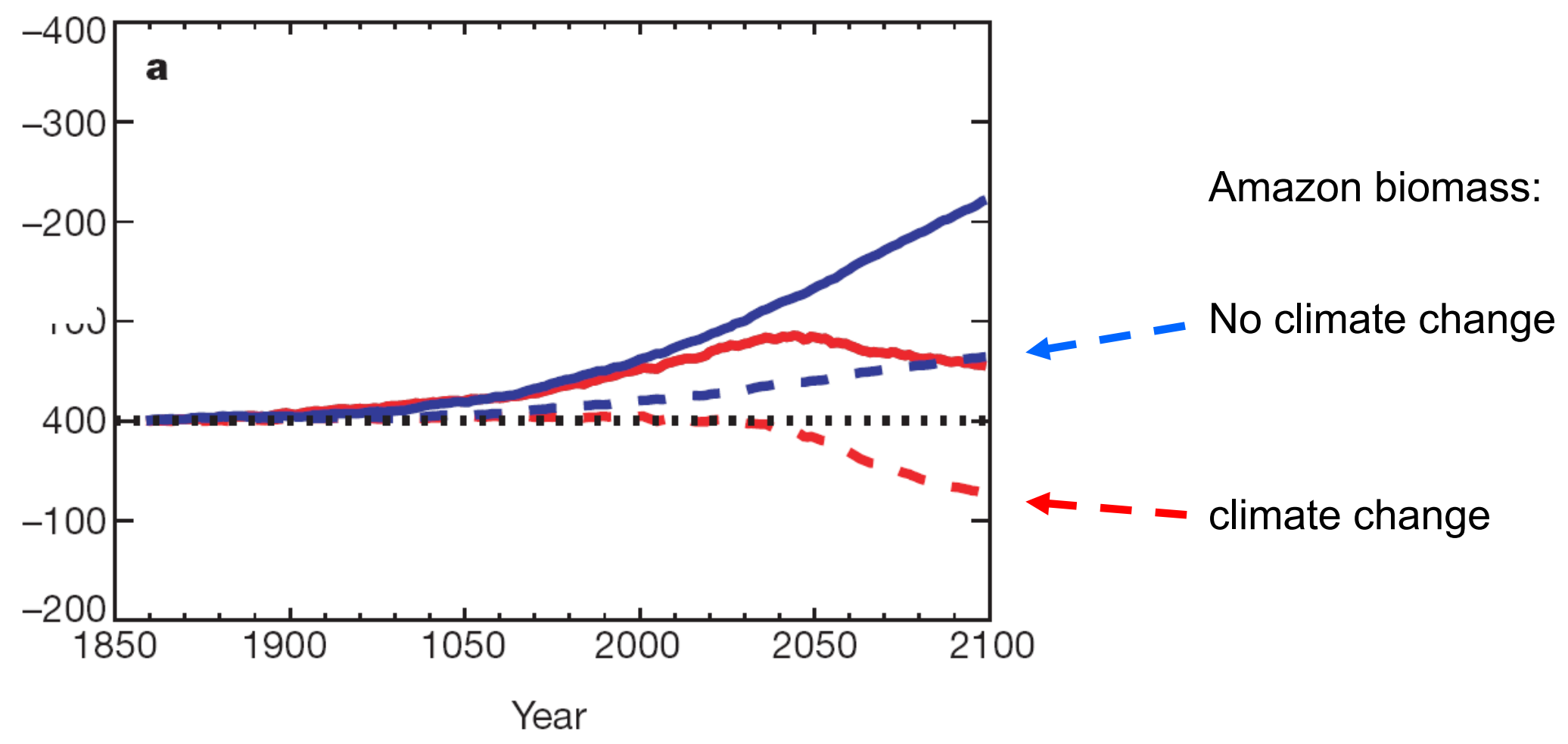

Effect of global warming on changes in land carbon storage. The red lines 


\section{Future vegetation changes}

\section{Met Office}

- Not just a feature of this model

- Also happens across different vegetation models (Cox et al., 2004, TAC)

- Also happens for different GCMs (Scholze et al., 2006, PNAS)
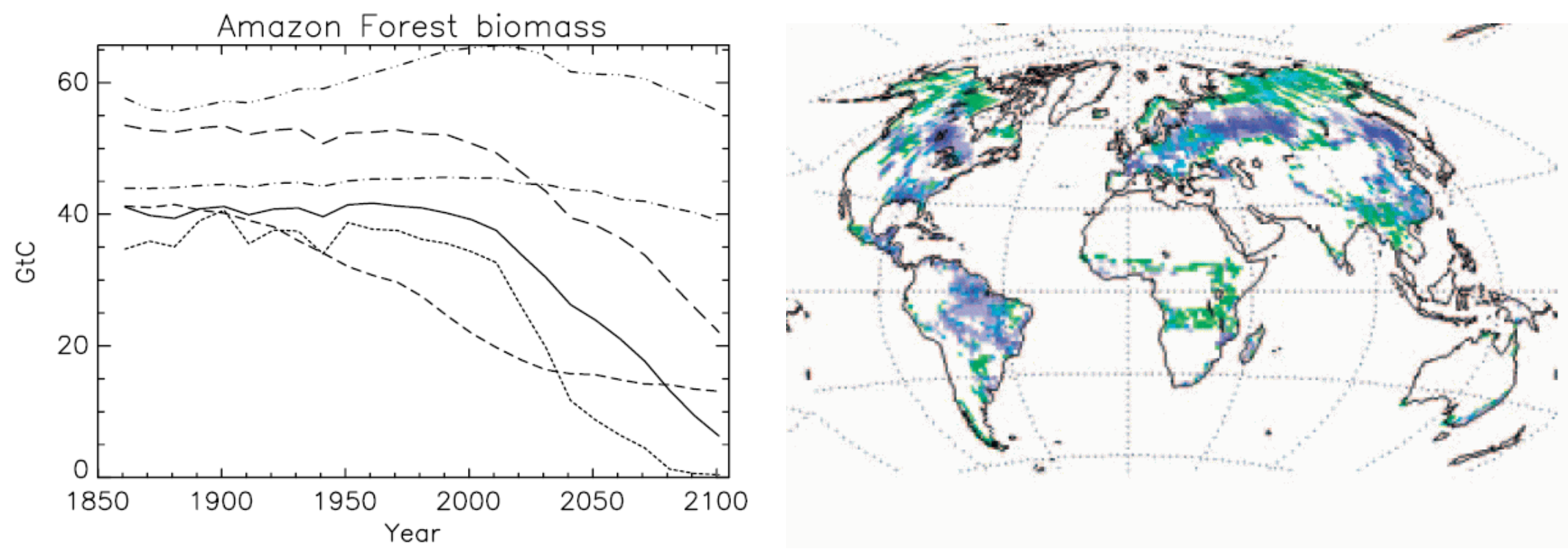


\section{Committed ecosystem changes}

\section{Met Office}

- But ecosystems have a long timescale to respond to environmental changes (in terms of composition/coverage)

- Continue to respond after forcing stabilises

- Start with business-as-usual A2 emissions scenario

- At 2012, 2050, 2100 cut emissions to zero
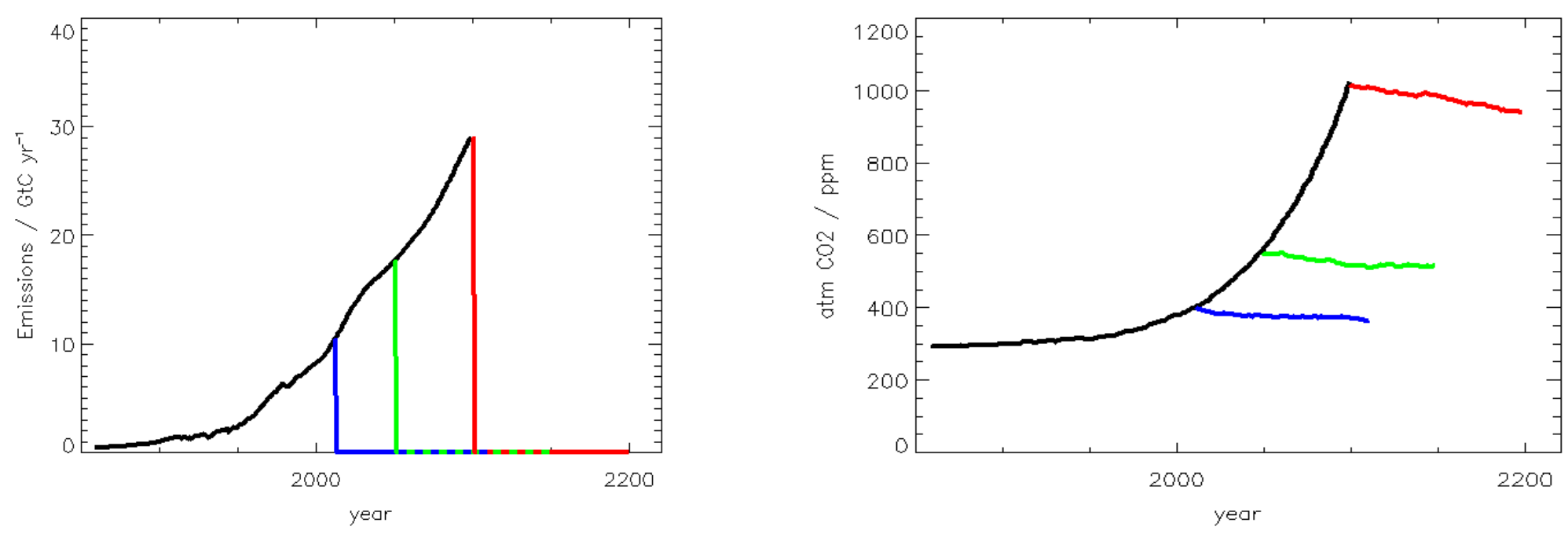

Lowe et al., 2009, ERL 


\section{Response of Amazon forest}

Met Office

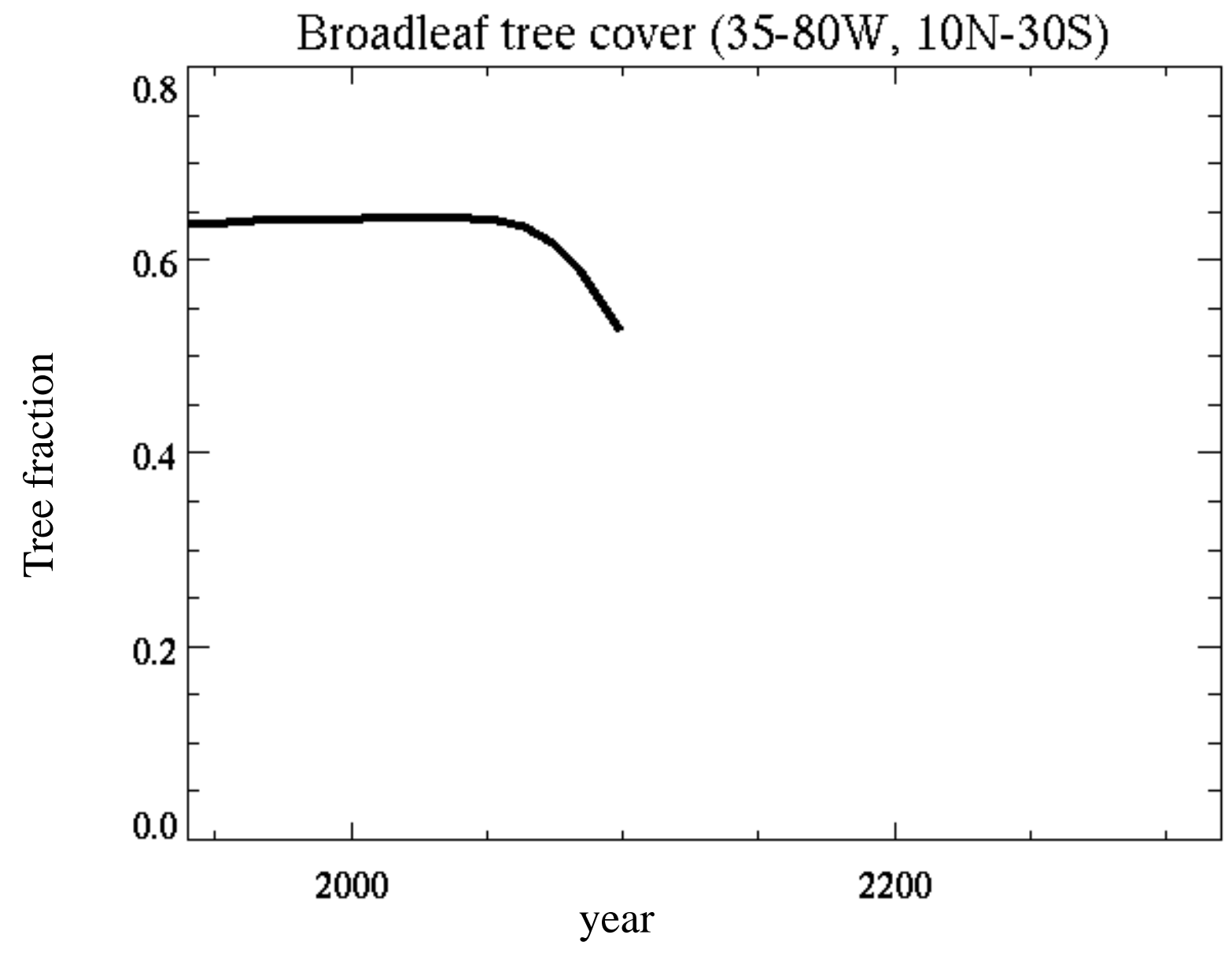

Significant future dieback predicted for "business as usual" A2 scenario 


\section{Response of Amazon forest}

Met Office

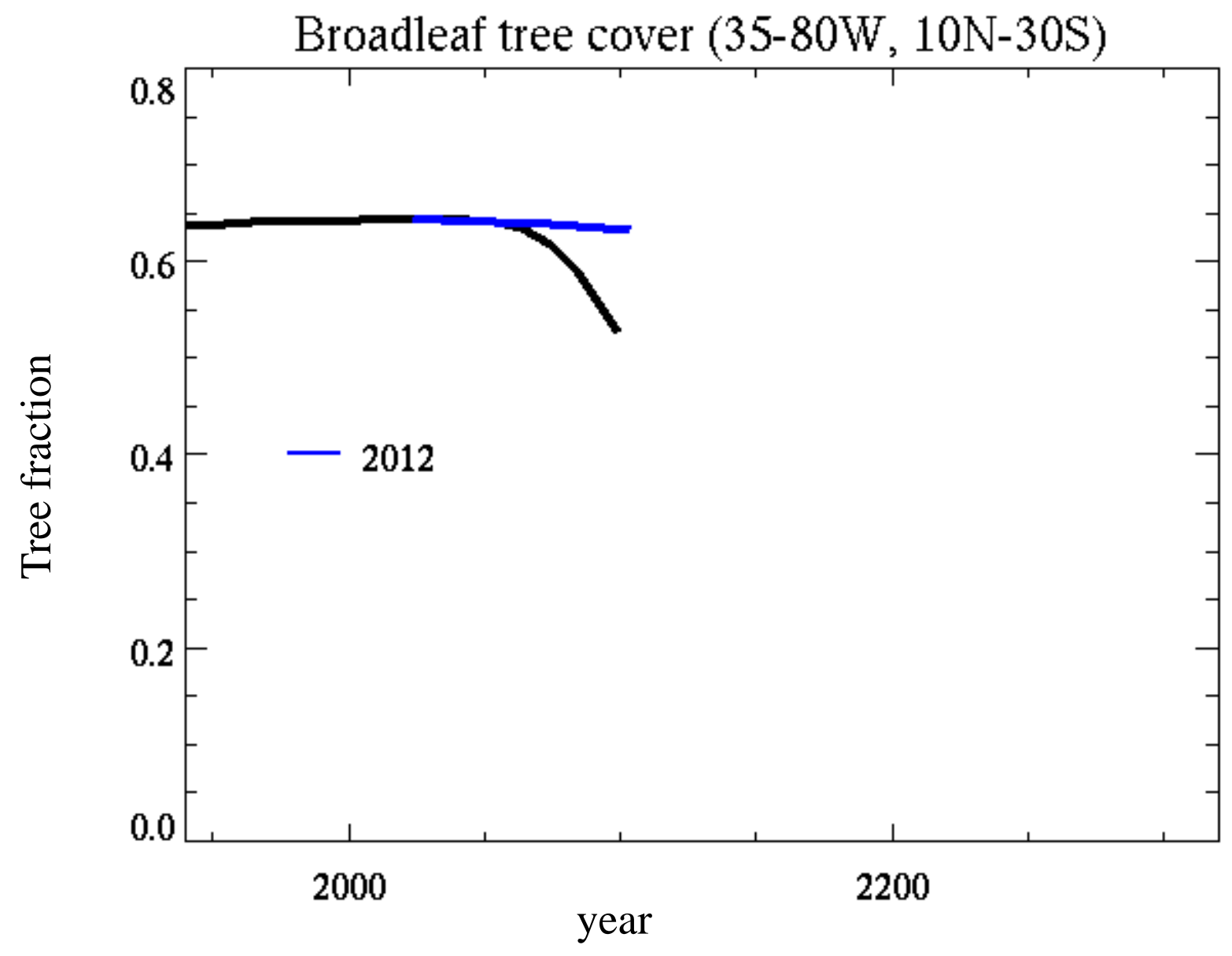

Emissions cuts at 2012 prevent future dieback 


\section{Response of Amazon forest}

Met Office

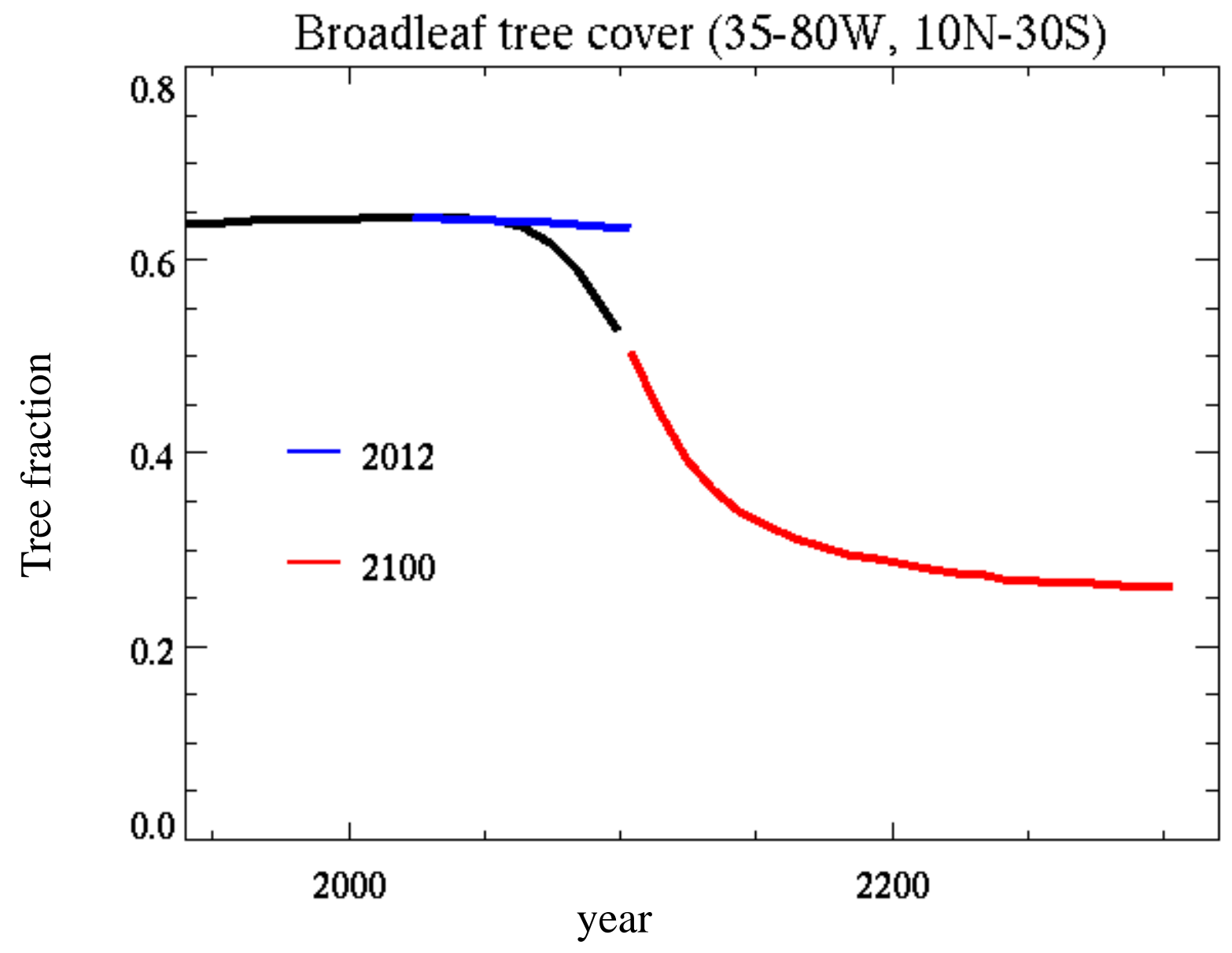

Emissions cuts at 2100 don't allow forest to recover

- continued severe dieback 


\section{Response of Amazon forest}

Met Office

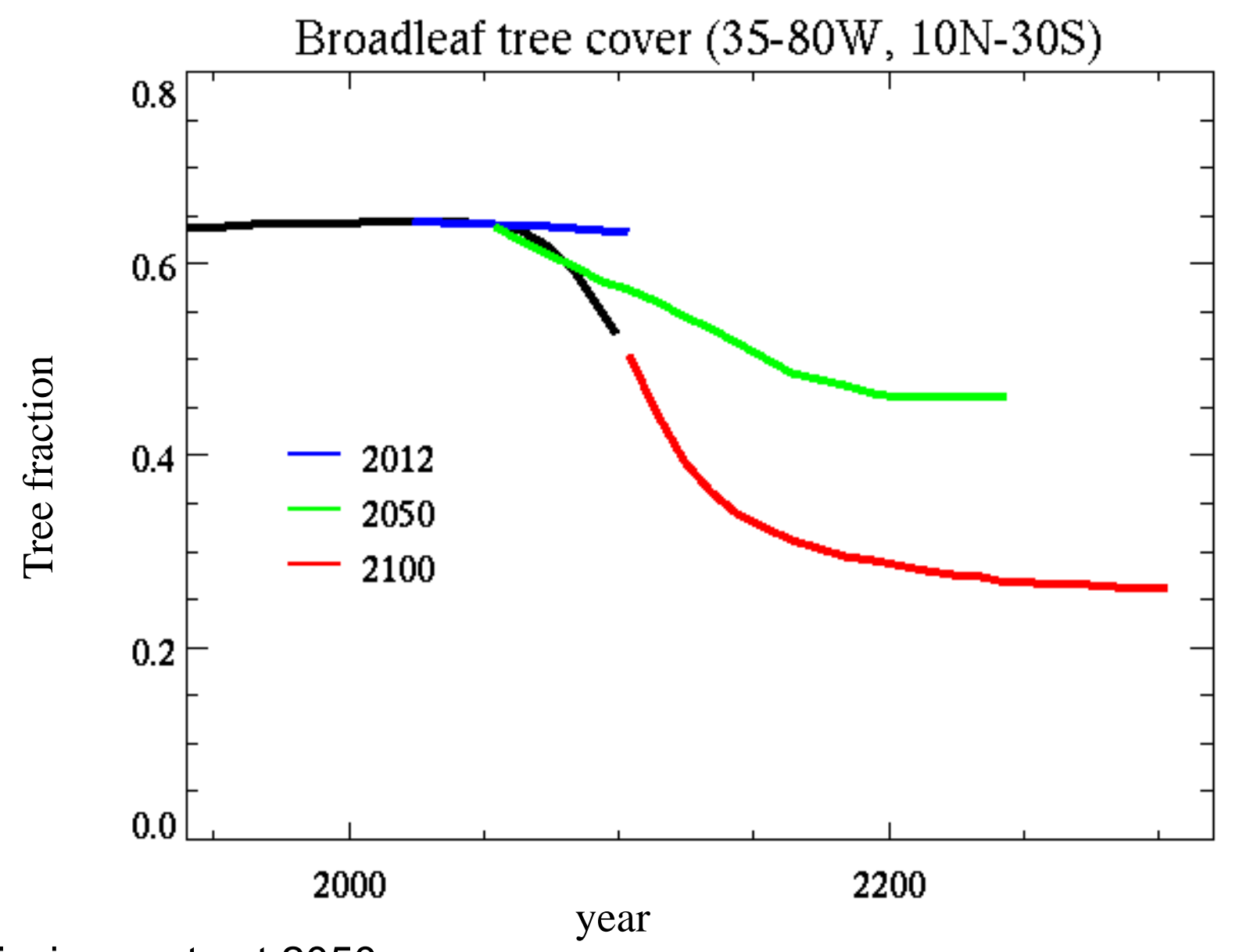

Emissions cuts at 2050:

- still see significant future dieback

- even though none apparent at time of cuts!

Must have crossed some climate threshold beyond which dieback is "committed" 
Metoffice changes

\section{Committed ecosystem}

- Concept of "committed changes" common in climate science

- Temperature, sea-level rise, ice sheets...

- Continue to respond after stabilisation of forcing

- Any component with "inertia" could exhibit this

- Ecosystems no exception

- No reason to suppose actual state at any time is in equilibrium with climate 


\section{Exploring ecosystem equilibria}

\section{Met Offiı}

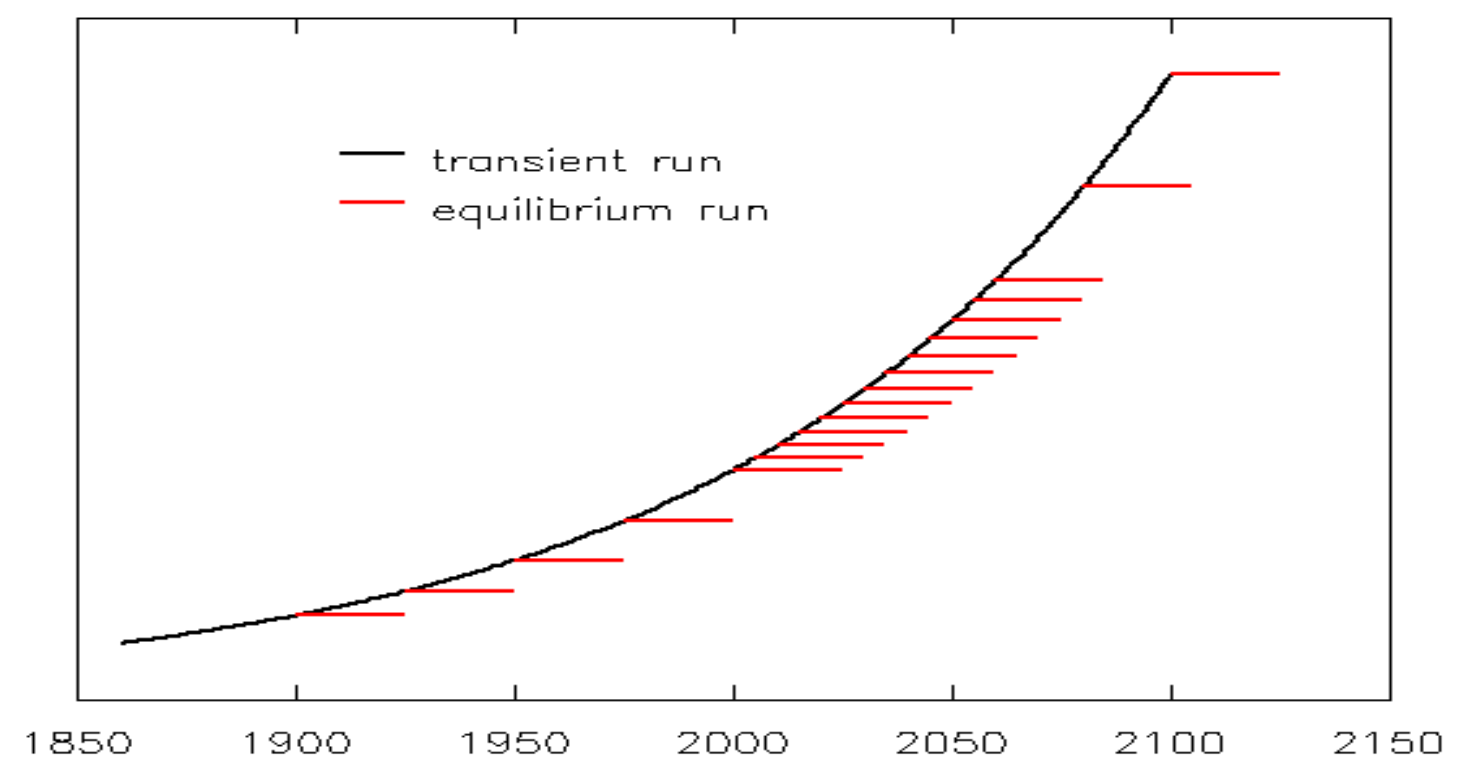

- Vegetation model, TRIFFID, has rapid spin-up equilibrium mode

- Run for 25 years following many points along transient path

- Obtain the equilibrium (committed) vegetation state corresponding to the "realised" state 


\section{Amazon case study}

\section{Met Office}

- Transient run shows significant dieback

- Becomes apparent after 2050

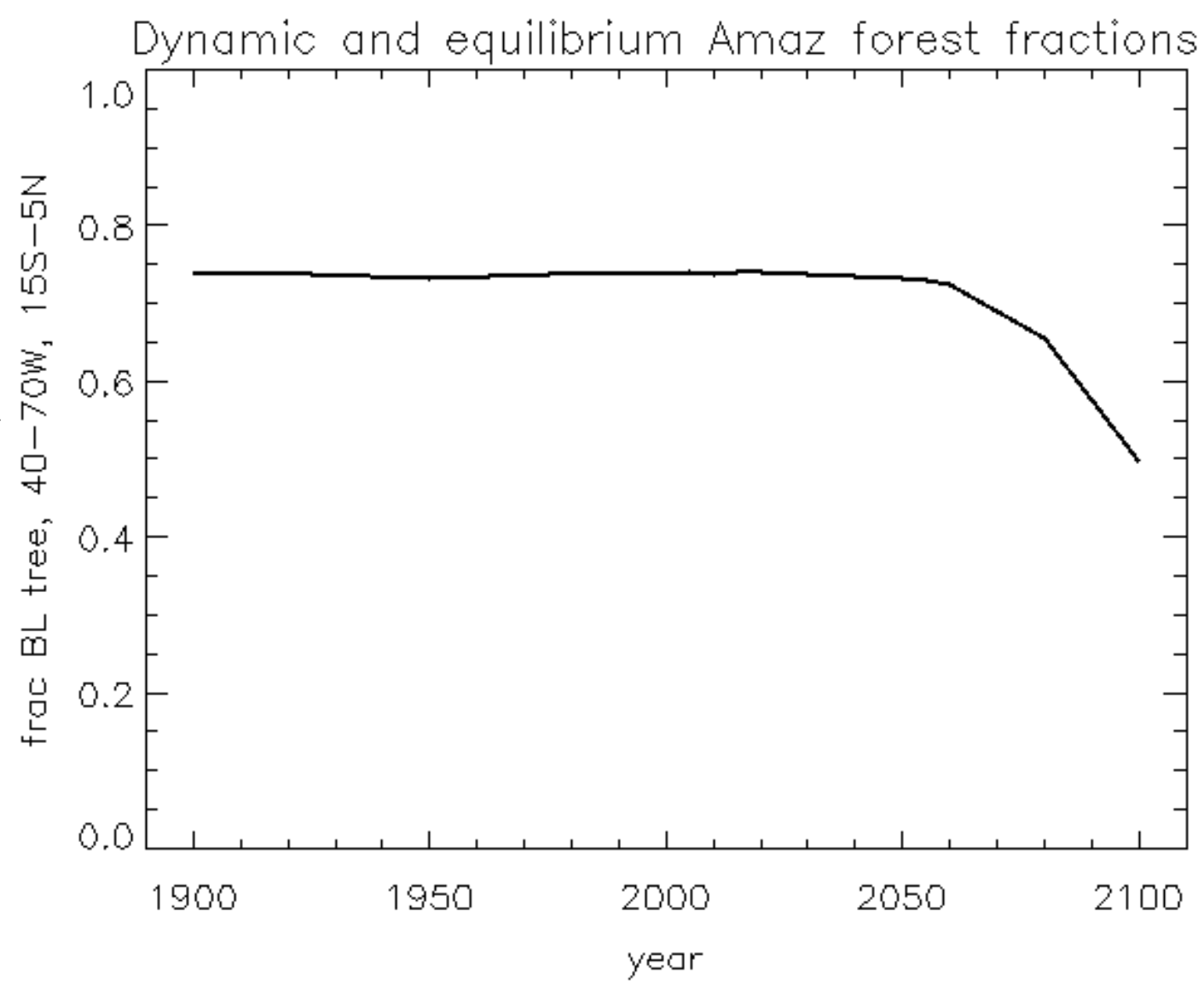




\section{Amazon case study}

Met Office

- Transient run shows significant dieback

- Becomes apparent after 2050

- Much greater committed changes

- Starting early $21^{\text {st }}$ century

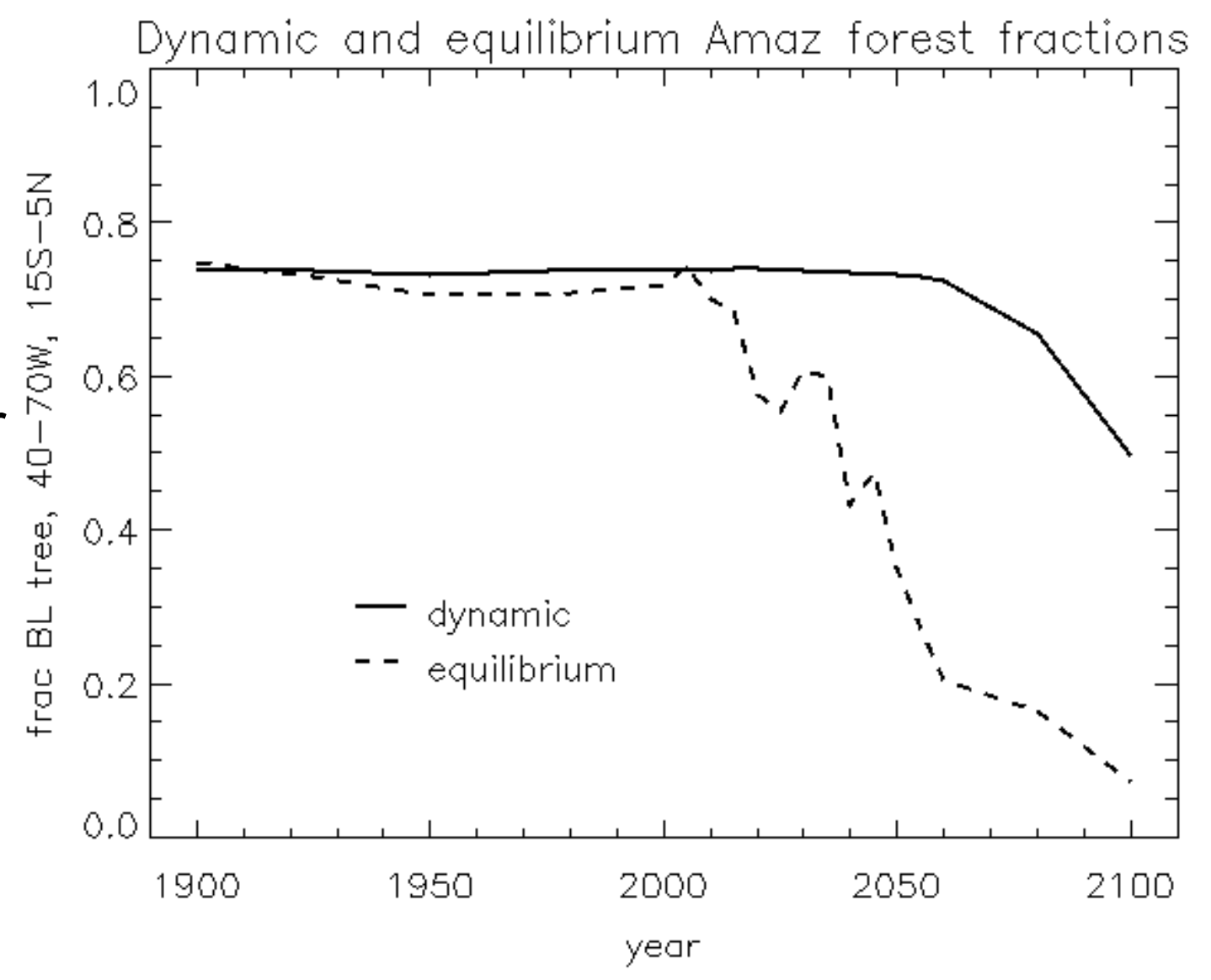

- But single-model study

- clearly magnitude of this is model dependent 


\section{DGVM intercomparison}

\section{Met Office}

- 2 axes of uncertainty

- Climate (GCM)

- Vegetation response to it (DGVM)

- Here explore the DGVM axis

- Use the IMOGEN framework

- Climate pattern-scaling approach to run land-surface models offline

- Run 5 DGVMs to equilibrium vegetation cover

- $\Delta \mathrm{T}=1,2,3,4,5$ degrees

- Note - not funded work. Many thanks to all groups involved for providing results.

- Hyland, LPJ, ORCHIDEE, Sheffield-DGVM, TRIFFID 


\section{IMOGEN vs GCM runs}

\section{Met Office}

- Compare the IMOGEN runs with TRIFFID against original GCM runs with TRIFFID

- Maps for committed changes at 5 degrees

- Tree cover

- Veg carbon

- Soil carbon

- Very similar patterns*

- * see caveat later

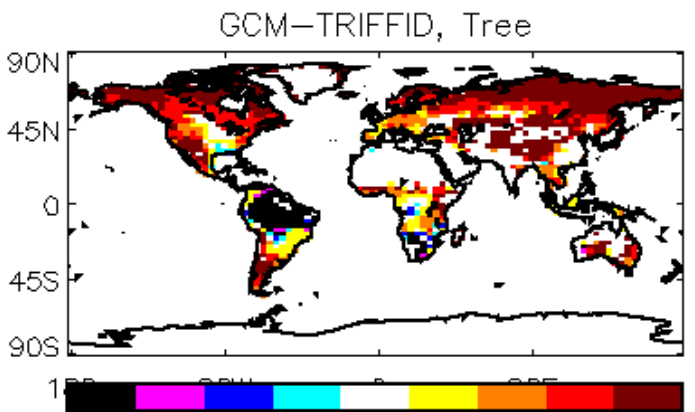

$\begin{array}{lllll}-0.2-0.1-0.05-0.010 .01 & 0.05 & 0.1 & 0.2\end{array}$

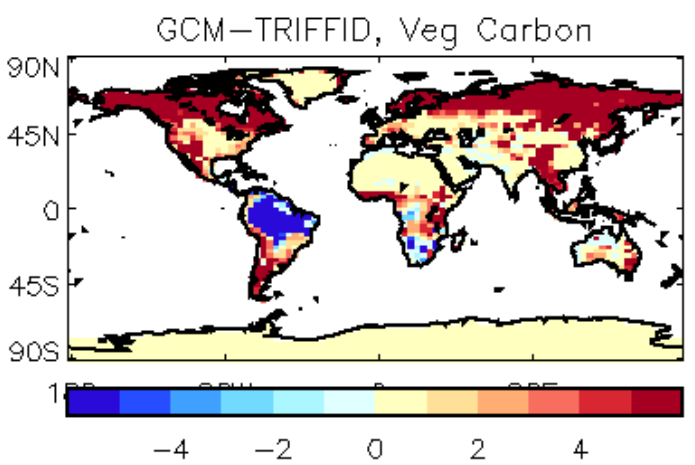

GCM-TRIFFID, Soil Carbon

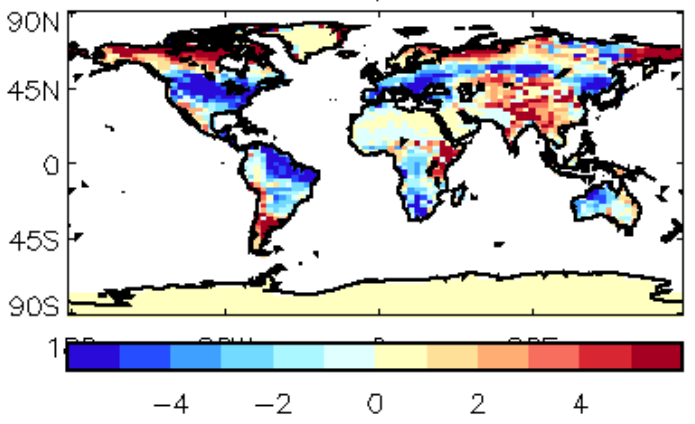

IMOGEN-TRIFFID, Tree
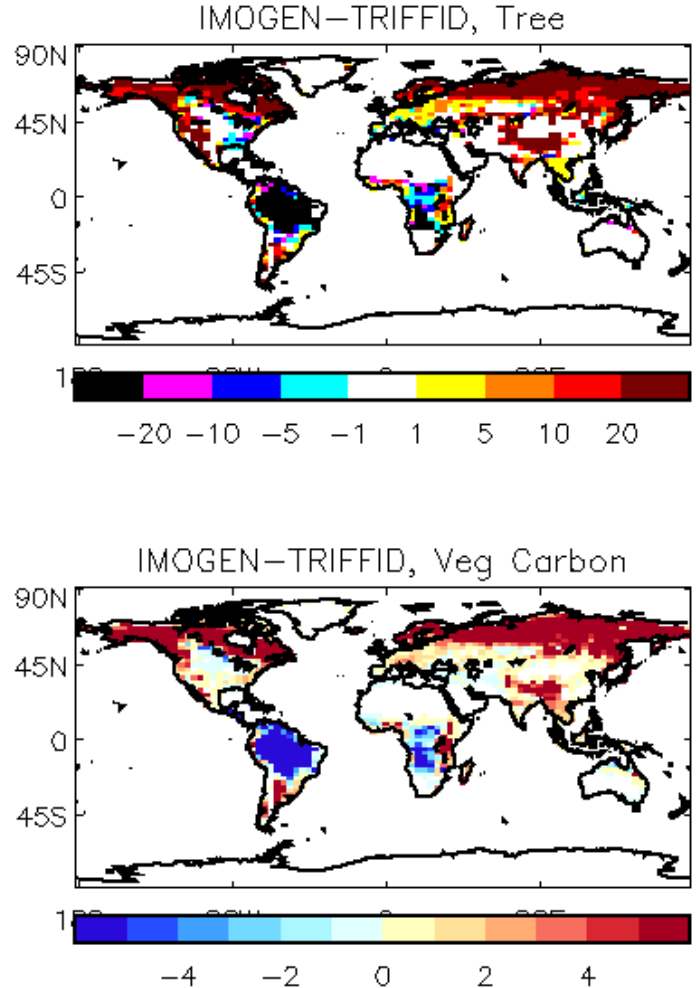

IMOGEN-TRIFFID, Soil Carbon

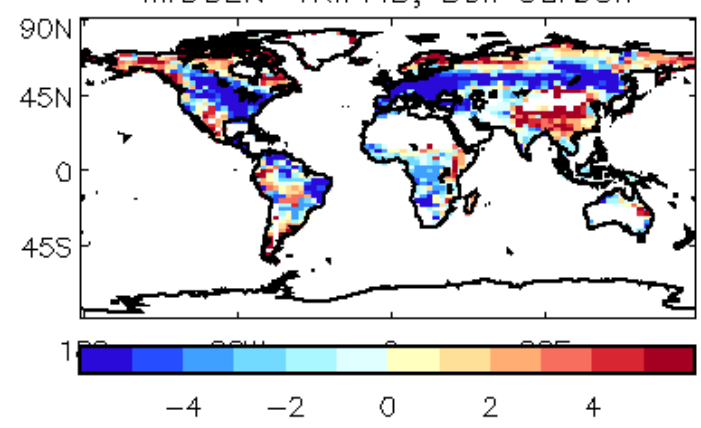




\section{GCM results in climate space}

\section{Met Office}

- Same results as before

- \%-dieback (positive upwards)

- against global temperature change.

Jones et al., 2009,

Nature Geoscience

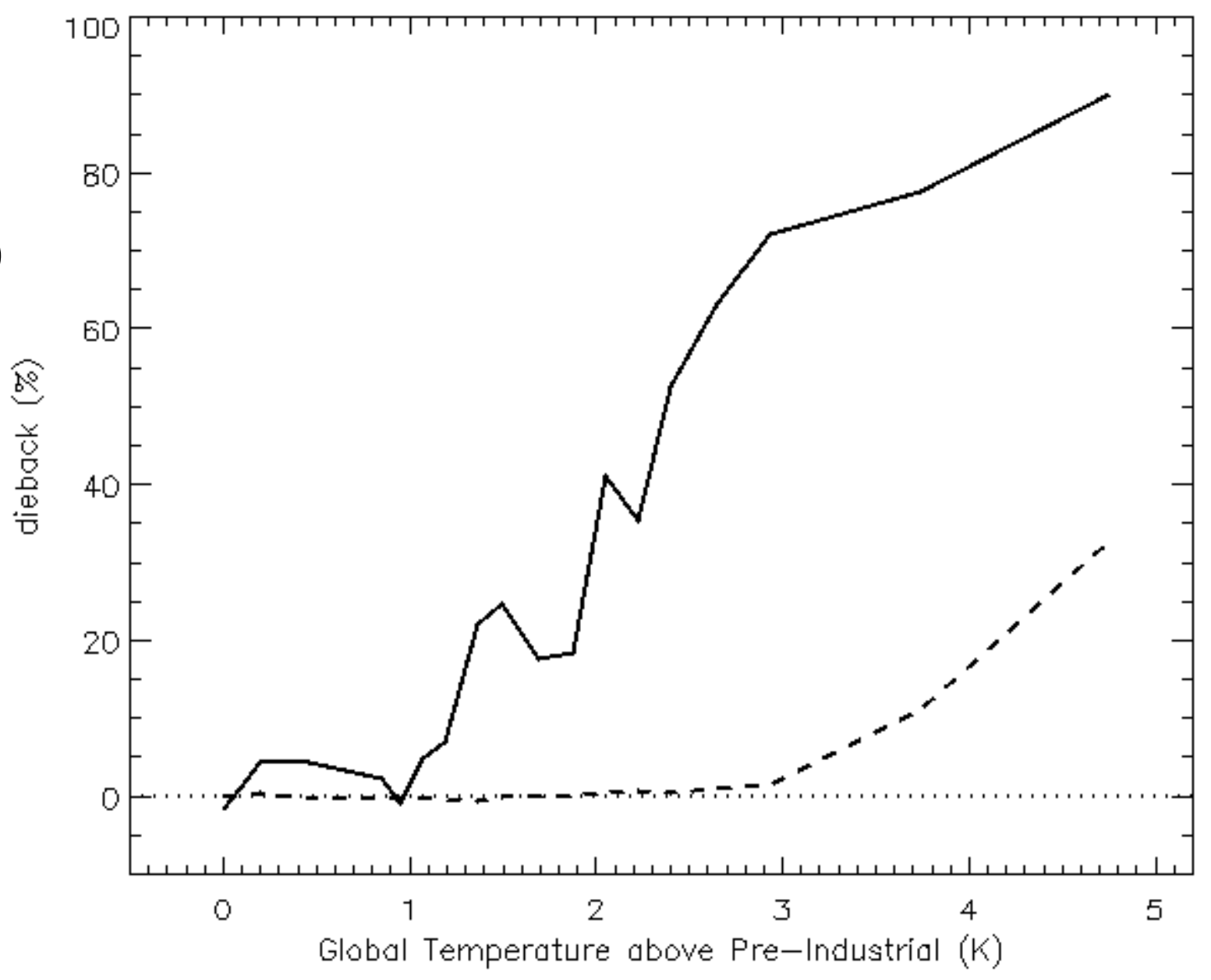




\section{Met Office}

\section{DGVM results - Amazon dieback uncertainty}

- All DGVMs see committed dieback

- Increases for greater climate change

- All greater than REALISED state in GCM

- TRIFFID has greatest dieback

- Remember - all DGVMs see identical climate here

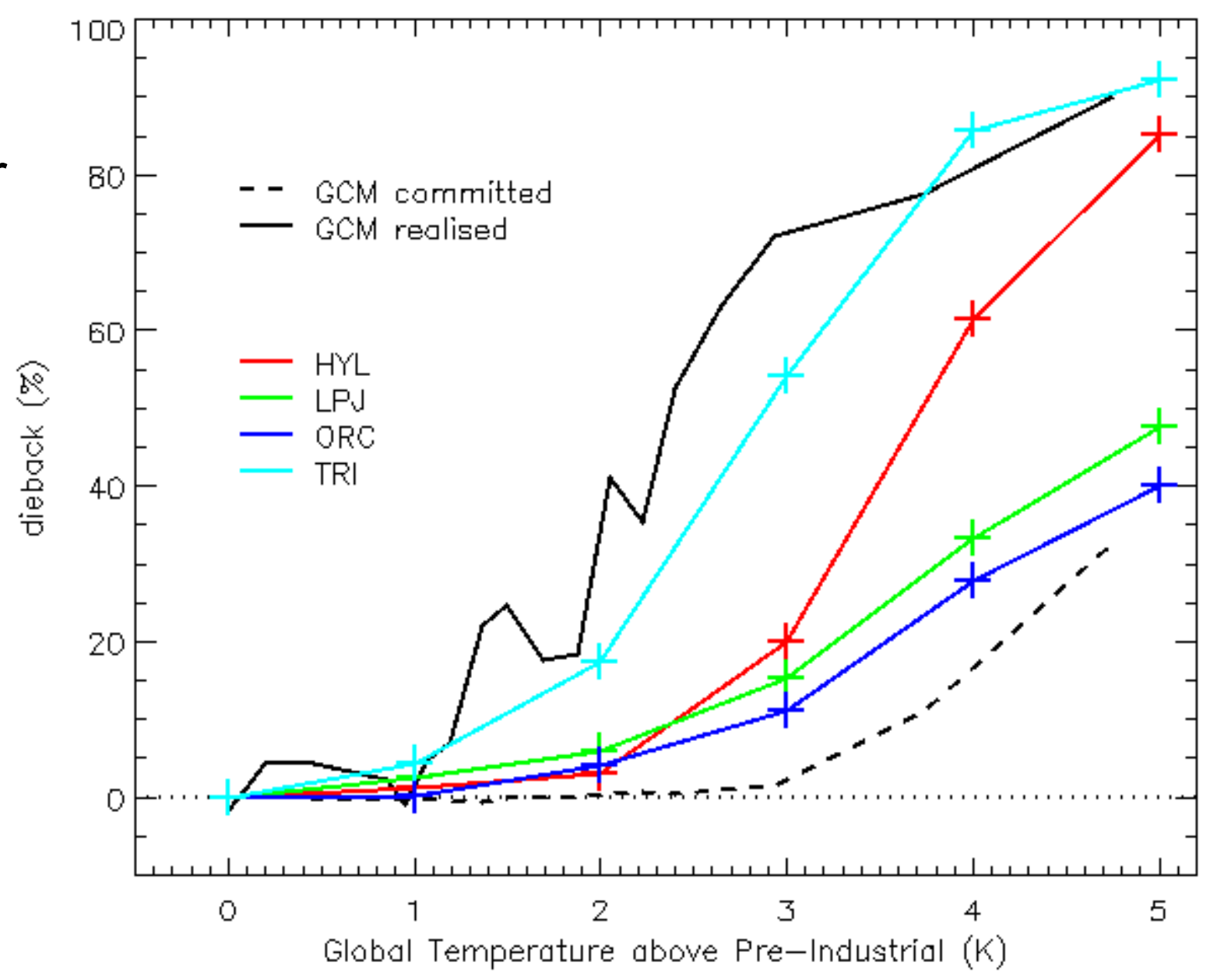




\section{Boreal forest results}

\section{Met Office}

- GCM simulated large expansion of Boreal forest

- Defined here as tree cover between $45 \mathrm{~N}$ $80 \mathrm{~N}$

- Transient (realised) response slow, therefore small.

- Committed response continues for centuries

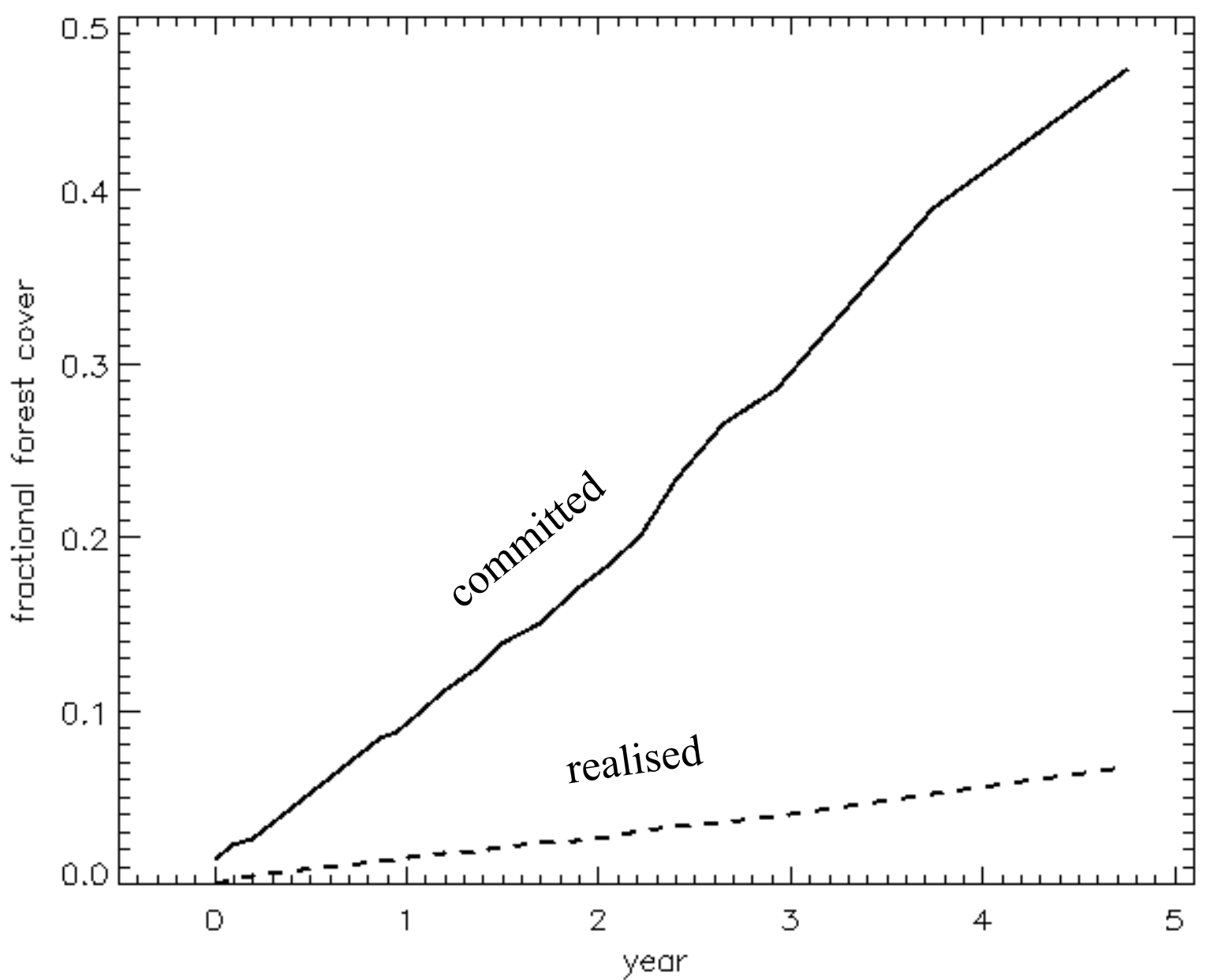

Jones et al., 2009, Nature Geoscience 


\section{Met Office}

\section{Boreal/temperate forest commitments}

- DGVM response markedly different for Boreal forest $(>60 \mathrm{~N})$ and temperate forest $(45-60 \mathrm{~N})$

- All see Boreal expansion (northward shift of tree line)

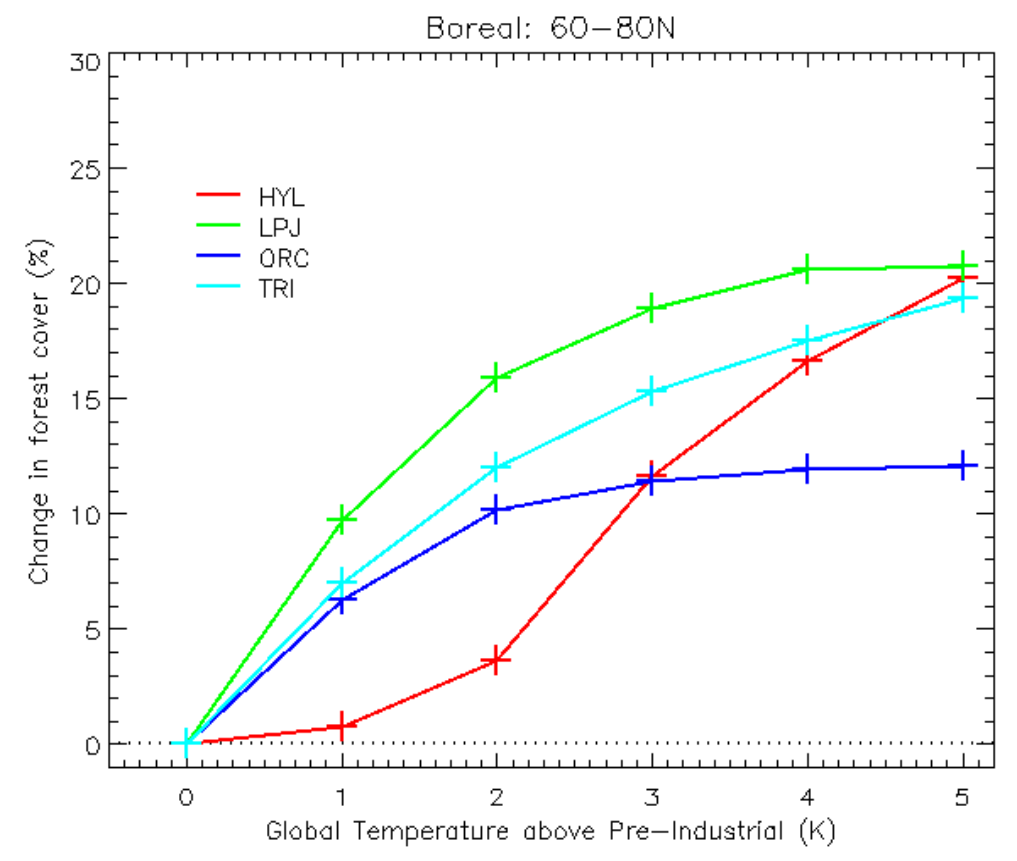




\section{Met Office}

\section{Boreal/temperate forest commitments}

- DGVM response markedly different for Boreal forest $(>60 \mathrm{~N})$ and temperate forest $(45-60 \mathrm{~N})$

- All see Boreal expansion (northward shift of tree line)

- Differ in sign of temperate response

- LPJ sees greatest boreal expansion AND greatest temperate loss...
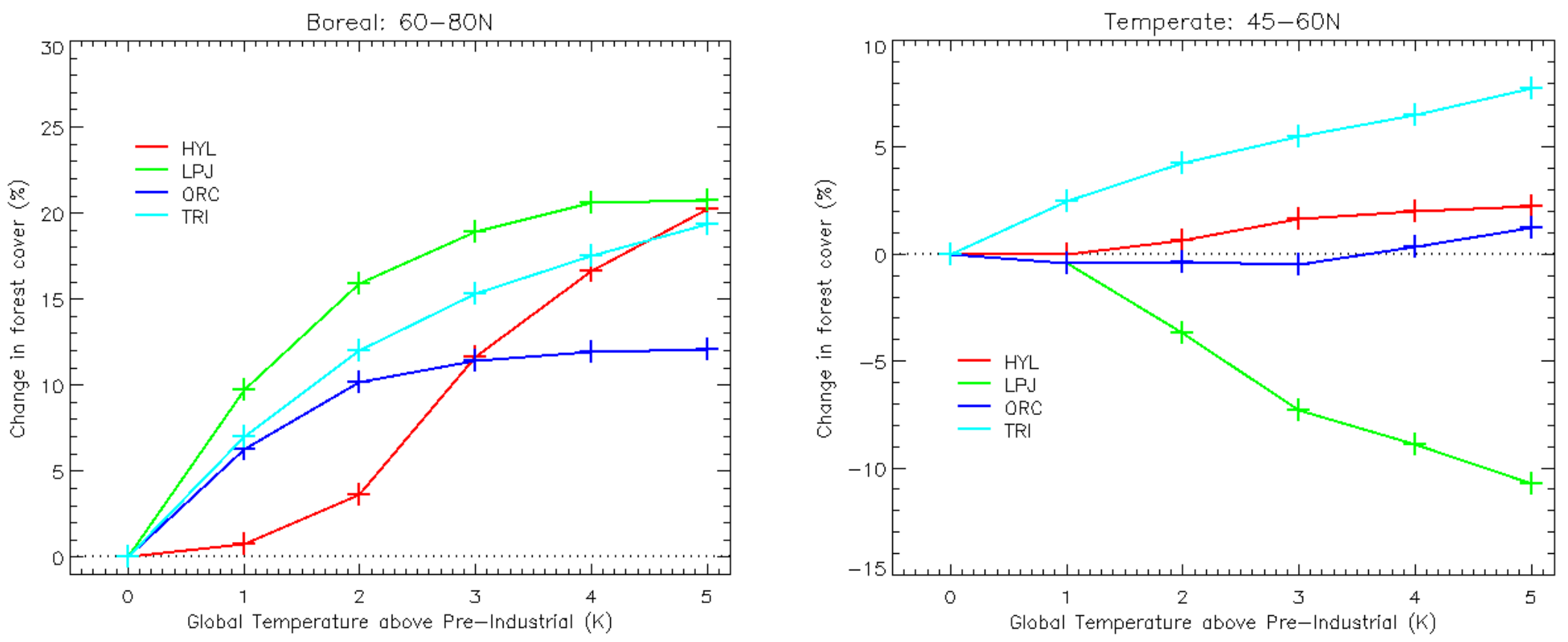


\section{Met Office}

\section{NPP: what
changes?}

- Amazon:

- All models simulate lower NPP. Except TRIFFID!

- See next slide

- All models see increase in temperate productivity including LPJ

- Large spread in magnitude

- Fire not yet investigated

- All models agree closely on increased Boreal productivity
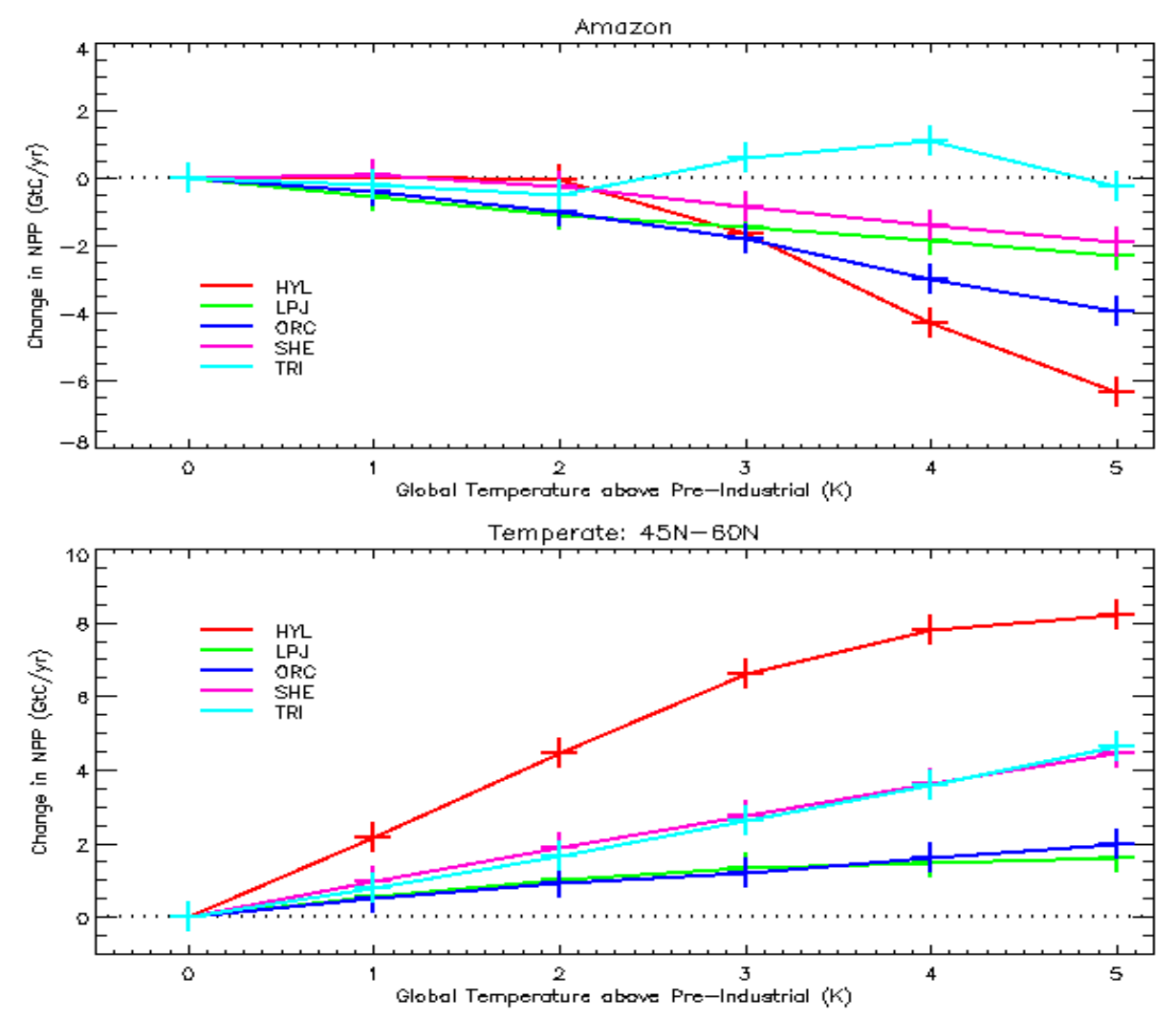

Boreal: $60 \mathrm{~N}-80 \mathrm{~N}$

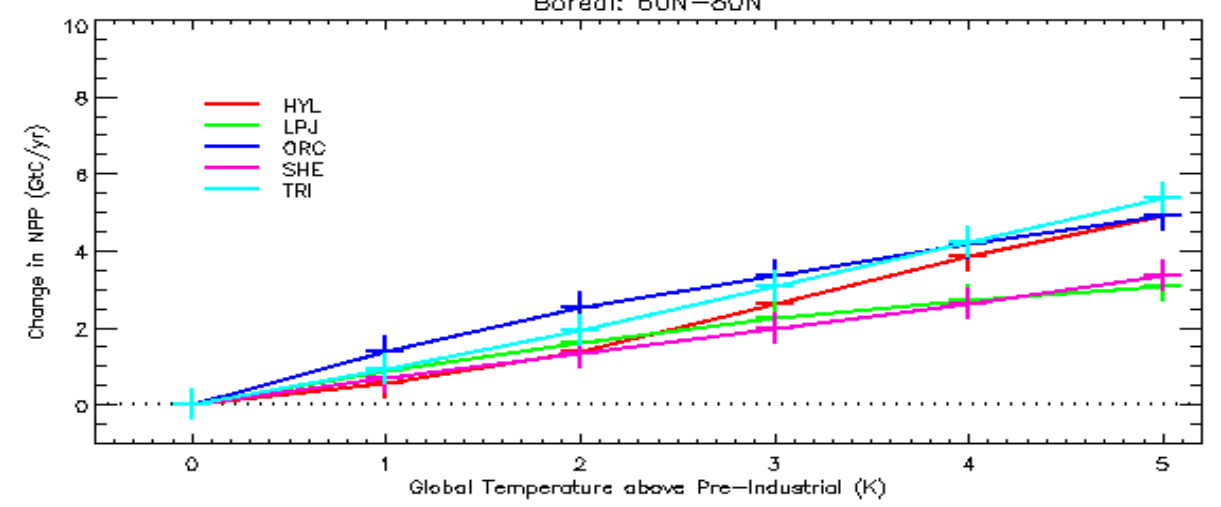




\section{Local feedbacks}

- Some interesting aspects requiring more investigation

\section{Met Office}

- TRIFFID showed largest Amazon dieback, but was only model with unchanged NPP

- GCM-TRIFFID simulates desertification. IMOGEN-TRIFFID simulates grass cover.

- Hence NPP not decreased in offline runs.

- ... importance of coupled GCM-vegetation modelling. Offline runs useful but can't do it all...
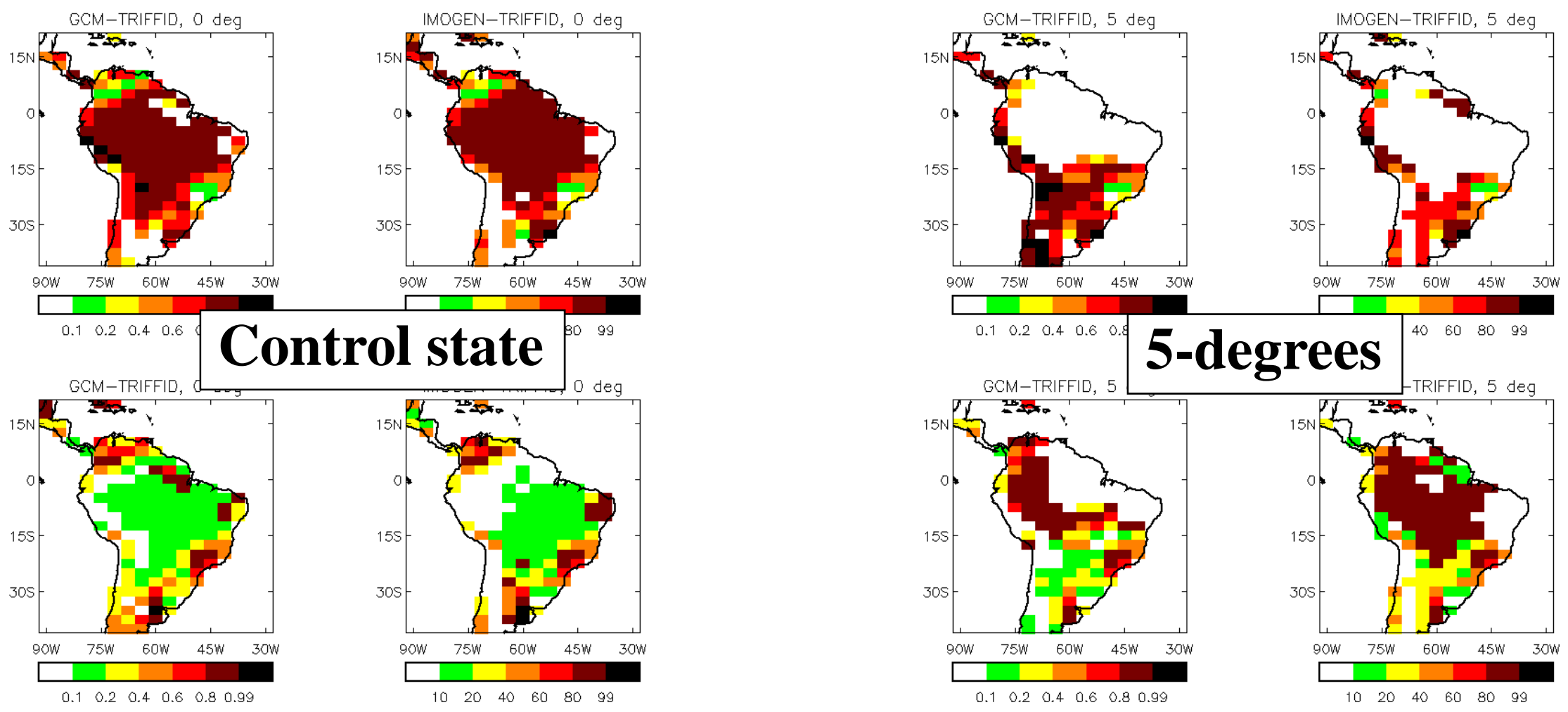


\section{Summary of results}

\section{Met Office}

- We explored the DGVM axis of uncertainty.

- So what's robust and what's uncertain?

- Boreal forest expansion

- strong agreement on magnitude of NPP increase. Spread in forest expansion, due to veg dynamics

- Amazon dieback

- general agreement on some dieback. Uncertainty in magnitude. This comes from uncertainty in both response of NPP to climate and veg dynamics

- Temperate forest

- agree on increased productivity, but uncertain in magnitude.

- Disagree on sign of forest cover changes

- Representation of PFTs? Inclusion of fire disturbance? 


\section{Conclusions}

\section{Met Office}

- Ecosystems exhibit significant commitment to change after climate stabilisation

- Response continues for decades or centuries after climate stabilised

- Quantitative nature of results very model dependent

- We have explored DGVM uncertainty

- Amazon forest could be committed to large-scale loss before any is apparent

- Boreal forest will expand northwards - probably for centuries after stabilisation

- Uncertainty is very large in temperate forest response and southern edge of boreal forest - disturbance processes require more study

- Work in hand (Chris H.) to explore GCM axis...

- Definitions of Dangerous Climate Change for slowly-responding components need to consider commitments, not just instantaneous state 


\section{References and contact}

\section{Met Office}

- $\mathrm{CO}_{2}$ recovery from overshoot is described in:

- Lowe et al., 2009, ERL, 4, "How difficult is it to recover from dangerous levels of global warming?"

- Committed ecosystem changes are described in:

- Jones et al., 2009, Nature Geoscience, 2, "Committed terrestrial ecosystem changes due to climate change"

- DGVM intercomparison of these 5 DGVMs under transient climate change in:

- Sitch et al., 2008, GCB, 14, "Evaluation of the terrestrial carbon cycle, ... using fiveDynamic Global Vegetation Models (DGVMs)"

more info - email: chris.d.jones@metoffice.gov.uk 